\title{
COMPORTAMENTO RESPIRATÓRIO E AMACIAMENTO DE GRAVIOLA (Annona muricata L.) APÓS TRATAMENTOS PÓS-COLHEITA COM CERA E 1-METILCICLOPROPENO
}

\author{
Respiratory behavior and softening of soursop fruit (Annona muricata L.) after \\ postharvest treatments with wax and 1-methylcyclopropene
}

\author{
Maria Auxiliadora Coêlho de Lima ${ }^{1}$, Ricardo Elesbão Alves $^{2}$, Heloísa Almeida Cunha Filgueiras ${ }^{3}$
}

\begin{abstract}
RESUMO
Avaliou-se o efeito da aplicação pós-colheita de 1-metilciclopropeno (1-MCP) e cera sobre o comportamento respiratório e as mudanças bioquímicas associadas ao amaciamento de graviola 'Morada', durante o armazenamento refrigerado. Os frutos, produzidos em Limoeiro do Norte-Ceará, foram colhidos na maturidade fisiológica. Os tratamentos utilizados foram: controle, 200 nL.L ${ }^{-1}$ de 1-MCP, pulverização com cera Fruit wax ${ }^{\circledast}$ e pulverização com Fruit wax ${ }^{\circledR}$ seguida da aplicação de $200 \mathrm{~nL}$. $\mathrm{L}^{-1}$ de 1-MCP. Os frutos foram armazenados por $0,4,8,11,13$ e 15 dias, a $15,4 \pm 1,1^{\circ} \mathrm{C}$ e $86 \pm 7 \%$ UR. Utilizou-se o delineamento experimental inteiramente casualizado, em fatorial 4x6, com quatro repetições. A partir do quarto e até o oitavo dia, observouse intensa atividade metabólica, acompanhada por rápida degradação de amido e aumento da atividade da $\beta$-galactosidase. Os tratamentos pós-colheita atrasaram ou reduziram a respiração e a produção de etileno. $\mathrm{O}$ amaciamento foi mais lento nos frutos tratados, principalmente entre o quarto e o oitavo dias. $\mathrm{O}$ tratamento cera+1-MCP reduziu temporariamente a atividade da poligalacturonase e manteve estável a da amilase. Entretanto, a cera foi o tratamento mais eficiente porque preservou a aparência por até treze dias.
\end{abstract}

Termos para indexação: Amido, annonaceae, conservação pós-colheita, enzimas hidrolíticas.

\section{ABSTRACT}

The effect of postharvest application of 1-methylcylopropene (1-MCP) and wax on respiratory behavior and biochemical changes was evaluated regarding the softening of soursop fruit 'Morada', during refrigerated storage. Fruits produced in Limoeiro do Norte, State of Ceara, Brazil, were harvested at the physiological maturity stage. The treatments were: control, $200 \mathrm{~nL} . \mathrm{L}^{-1}$ of 1-MCP, Fruit wax ${ }^{\circledR}$ sprayed on fruits, and Fruit wax ${ }^{\circledR}$ sprayed on fruits followed by application of $200 \mathrm{~nL} . \mathrm{L}^{-1}$ of 1-MCP. The fruits were stored during $0,4,8,11,13$ and 15 days, at $15.4 \pm 1.1^{\circ} \mathrm{C}$ and $86 \pm 7 \% \mathrm{RH}$. A completely randomized experimental design was used, with a $4 \times 6$ factorial and four replications. From the fourth day to the eighth day, an intense metabolic activity was observed, as well as a fast starch breakdown and an increase in $\beta$-galactosidase activity. Postharvest treatments delayed or reduced respiration and ethylene production. Softening was slower in treated fruits mainly between the fourth and the eighth day. The treatment wax coating+1-MCP temporarily reduced polygalacturonase activity and kept amylase activity stable. However, wax was the most efficient treatment because it maintained the appearance during thirteen days.

Index terms: Starch, annonaceae, postharvest conservation, hydrolytic enzymes.

(Recebido em 10 de agosto de 2007 e aprovado em 23 de abril de 2009)

\section{INTRODUÇÃO}

A alta perecibilidade da graviola e o curto período de conservação após a colheita (Aziz \& Yusof, 1994) têm sido responsáveis por altos índices de perdas e por dificuldades no abastecimento de mercados tradicionais e potenciais de consumo da fruta fresca.

Apesar dos problemas de conservação póscolheita, a graviola ainda é uma fruta pouco estudada. Os trabalhos, em geral, têm caracterizado alterações na cor da casca e no teor de açúcares, de ácidos orgânicos e de compostos fenólicos da polpa (Paull et al., 1983; Aziz \& Yusof, 1994). Adicionalmente, estudos realizados por Lima et al. (2006) apresentaram informações sobre as principais mudanças relacionadas ao amaciamento da graviola, por meio de determinações físicas e de eventos químicos e bioquímicos, durante a maturação pós-colheita, sob temperatura ambiente.

A essas informações precisam ser agregadas outras que possam elucidar o metabolismo desse fruto como requisito para o estudo de técnicas de conservação

\footnotetext{
${ }^{1}$ Embrapa Semi-Árido - BR 428, km 152, - Cx. P. 23 - 56.302-970 Petrolina, PE - maclima@cpatsa.embrapa.br ${ }^{2}$ Embrapa Agroindústria Tropical - Fortaleza, CE ${ }^{3}$ Embrapa Agroindústria Tropical - Fortaleza, CE
} 
eficazes e adequadas aos padrões de qualidade dos diferentes mercados.

No que se refere a tecnologias pós-colheita, alguns estudos estão sendo realizados. O emprego da refrigeração foi avaliado por Silva et al. (2001) e Lima et al. (2004). Ambos os estudos testaram inclusive a associação do armazenamento refrigerado a outras técnicas. Silva et al. (2001) obtiveram incremento da vida útil dos frutos a partir do uso de filmes poliméricos. Por sua vez, Lima et al. (2004) avaliaram o efeito de um inibidor de etileno, o 1metilciclopropeno (1-MCP), e de cera na conservação e qualidade da graviola, caracterizando respostas sobre a perda de massa, coloração, acidez titulável, sólidos solúveis e açúcares.

O 1-MCP tem sido uma ferramenta útil para preservar a qualidade de alguns frutos (Valero et al., 2003, 2005; Argenta et al., 2005; Hershkovitz et al., 2005). Esse composto inibe a ação do etileno, competindo por seus sítios de ligação nos receptores membranares. Embora essa ligação seja irreversível, a sensibilidade ao etileno é recuperada através da renovação ou produção de novos sítios receptores (Sisler \& Serek, 1997).

O uso de ceras, por sua vez, tem o objetivo de formar uma barreira à transmissão de vapor de água e gases, permitindo reduzir a perda de massa durante o armazenamento (Jeong et al., 2003; Ergun et al., 2005). Em graviola, a aplicação de emulsão à base de polietileno e resina fumárica limitou a perda de água em frutos armazenados a $15^{\circ} \mathrm{C}$ (Lima et al., 2004).

Objetivou-se, no presente trabalho avaliar o efeito da aplicação pós-colheita de 1-MCP e cera sobre o comportamento respiratório e as mudanças bioquímicas associadas ao amaciamento de graviola 'Morada', durante $\mathrm{o}$ armazenamento refrigerado.

\section{MATERIAL E MÉTODOS}

Graviolas 'Morada', provenientes de pomar situado em Limoeiro do Norte, Ceará, foram colhidas na maturidade fisiológica, reconhecida através da maior separação entre as terminações estilares, que começavam a perder consistência.

Foram avaliados a aplicação de tratamentos póscolheita e o tempo de armazenamento. Os tratamentos póscolheita foram: controle; 200 nL.L $\mathrm{L}^{-1}$ de 1 -MCP (SmartFresh ${ }^{\mathrm{TM}}, 0,14 \%$ i.a.); pulverização com a cera Fruit $w a x^{\circledast}$ (emulsão de polietileno, resina fumárica, preservante e água); pulverização com Fruit wax ${ }^{\circledast}$ seguida da aplicação de 200 nL.L L $^{-1}$ de 1-MCP.

Para a aplicação do 1-MCP, os frutos foram acondicionados em caixas herméticas $\left(0,186 \mathrm{~m}^{3}\right)$ e expostos ao composto, na forma de gás, durante 12 horas sob temperatura de $15,4 \pm 1,1^{\circ} \mathrm{C}$ e $86 \pm 7 \%$ UR. Essas condições foram mantidas durante o período de armazenamento, sendo as avaliações realizadas aos $0,4,8,11,13$ e 15 dias.

As variáveis analisadas foram:

a) atividade respiratória $\left(\mathrm{mg} \mathrm{CO} \cdot \mathrm{kg}^{-1} \cdot \mathrm{h}^{-1}\right)$ : determinada a partir de $5 \mathrm{~mL}$ da amostra da atmosfera produzida pelo fruto intacto em recipiente fechado e injetada em cromatógrafo a gás, através de detector de condutividade térmica $\left(150^{\circ} \mathrm{C}\right)$, em coluna PORAPAK $-\mathrm{N}$ (4 $\mathrm{m} \times 3,2 \mathrm{~mm}$ ), usando $\mathrm{H}_{2}$ como gás de arraste $\left(30 \mathrm{~mL} \mathrm{~min}^{-1}\right)$ a uma temperatura de $60^{\circ} \mathrm{C}$ na coluna;

b) produção de etileno $\left(\mathrm{mL} \cdot \mathrm{kg}^{-1} \cdot \mathrm{h}^{-1}\right)$ : determinada em cromatógrafo a gás através de detector de ionização de chama $\left(200^{\circ} \mathrm{C}\right)$, com as demais características já descritas e a partir da mesma amostra de $5 \mathrm{~mL}$ coletada para determinação da atividade respiratória;

c) firmeza da polpa $(\mathrm{N})$ : obtida por meio de texturômetro, dotado de ponteira de $6 \mathrm{~mm}$ de diâmetro e ajustado para a distância de penetração de $20 \mathrm{~mm}$, à velocidade de $2,0 \mathrm{~mm} \cdot \mathrm{s}^{-1}$;

d) amido (g.100 g-1): a extração foi realizada por hidrólise ácida (AOAC, 1992), em cujo filtrado se determinou o teor de açúcares redutores (Miller, 1959). Multiplicando-se os resultados por 0,9, obteve-se o rendimento da conversão do amido em glicose, na hidrólise;

e) substâncias pécticas totais $\left(\mathrm{g} .100 \mathrm{~g}^{-1}\right)$ : a extração e a quantificação seguiram recomendações respectivas de McReady \& McComb (1952) e Blumenkrantz \& AsboeHansen (1973);

f) atividade da amilase $\left(\mu \mathrm{mol} \mathrm{maltose} \cdot \mathrm{g}^{-1} \cdot \mathrm{min}^{-1}\right)$ : a extração e o doseamento seguiram o método descrito por Bernfeld (1955), modificado por Khader (1992);

g) atividade da poligalacturonase $\left(\mathrm{PG}, \mathrm{UAE} \cdot \mathrm{g}^{-1} \cdot \mathrm{min}^{-1}\right)$ : a extração seguiu a recomendação de Jen \& Robinson (1984), sendo os grupos redutores liberados determinados segundo Miller (1959). Admitiu-se 1 UAE (Unidade de Atividade Enzimática) como a quantidade de enzima que catalisa a formação de $1 \mathrm{nmol}$ de grupos redutores por minuto;

h) atividade da $\beta$-galactosidase $\left(\beta\right.$-GAL, UAE.g $\left.{ }^{-1} \cdot \mathrm{min}^{-1}\right)$ : a extração foi realizada conforme Kitagawa et al. (1995) e a atividade da enzima localizada na parede celular determinada segundo Dey \& Pridham (1969), considerando-se 1 UAE como a quantidade de atividade da enzima que produziu uma mudança de 0,001 unidade de absorbância.

i) aparência: avaliada por três julgadores através de escala de notas, adaptada de Silva et al. (2001), onde 4= fruto firme, pseudoacúleos firmes e carnosos, ausência de injúrias na casca, manchas e/ou podridão; $3=$ ligeira perda 
de firmeza do fruto e dos pseudoacúleos, ausência de injúrias, manchas e/ou podridão; $2=$ perda intermediária da firmeza do fruto, pseudoacúleos flácidos, ausência de injúrias, manchas e/ou podridão; $1=$ perda acentuada da firmeza do fruto, pseudoacúleos flácidos e escuros, presença de manchas escuras e/ou injúrias leves; e $0=$ perda completa de firmeza do fruto, pseudo-acúleos ressecados e escuros, presença de manchas escuras e injúrias em intensidade moderada a severa e/ou podridão.

Utilizou-se o delineamento experimental inteiramente casualizado, em fatorial 4x6 (tratamentos póscolheita $\mathrm{x}$ tempo de armazenamento), com quatro repetições, exceto os tratamentos 1-MCP e cera+1-MCP, avaliados aos quatro dias, que tiveram uma parcela perdida. Cada parcela foi constituída por um fruto.

As variáveis atividade respiratória e produção de etileno foram avaliadas a intervalos mais frequentes a fim de caracterizar-se o padrão respiratório do fruto. Uma vez que não apresentaram homocedasticidade de variâncias, foram representadas por suas médias e erros-padrões da média. Para as demais, procedeu-se às análises de variância e, quando o tempo de armazenamento ou a interação entre os fatores foram significativos, de regressão polinomial. Admitiram-se equações de até $3^{\circ}$ grau e coeficientes de determinação superiores a 0,70 .

\section{RESULTADOS E DISCUSSÃO}

Os tratamentos pós-colheita influenciaram diferencialmente a atividade respiratória da graviola mas indicaram que sua característica particular de apresentar dois picos de $\mathrm{CO}_{2}$ se mantém mesmo sob refrigeração (Figura 1A). O primeiro pico respiratório foi verificado aos quatro dias, nos frutos dos tratamentos controle, cera e cera + 1-MCP. O segundo foi mais duradouro no controle, estendendo-se do nono até o décimo segundo dia. Porém, as maiores liberações de $\mathrm{CO}_{2}$ foram observadas nos frutos tratados com cera e cera +1 -MCP. Nos frutos submetidos apenas ao 1-MCP, os picos ocorreram no sexto e no décimo primeiro dia.

Vários estudos têm destacado a eficiência 1-MCP na redução da respiração e no atraso do pico climatérico (Valero et al., 2003; Argenta et al., 2005; Hershkovitz et al., 2005). Por sua vez, a aplicação de ceras não tem resultado em alterações metabólicas marcantes. Jeong et al. (2003) citaram que a aplicação de ceras em abacates não influenciou o padrão climatérico ou a magnitude do pico respiratório. Por outro lado, em mamey, a aplicação de cera antecipou o pico climatérico (Ergun et al., 2005).

A produção de etileno começou a ser detectada aos quatro dias nos frutos do controle e do tratamento com 1-MCP, sendo registrada nos demais a partir do quinto dia (Figura 1B). O aumento foi contínuo até atingir o pico: ao décimo primeiro dia, nos tratamentos controle, 1-MCP e cera, e ao décimo segundo dia, para o tratamento cera +1 MCP. Apesar dos maiores valores de etileno até o oitavo dia, os frutos controle apresentaram pico inferior ao dos tratamentos cera e cera + 1-MCP. O menor pico de etileno foi observado com uso do 1-MCP.

À semelhança da atividade respiratória, as produções de etileno nos frutos tratados com cera e cera + 1-MCP foram menores até o oitavo dia, quando iniciava o aumento para os picos climatérico e de etileno. É possível que a barreira superficial oferecida pela cera tenha limitado a disponibilidade interna de oxigênio, que é requerido na rota biossintética de etileno.

O emprego do 1-MCP geralmente reduz a produção de etileno e atrasa o pico (Jeong et al., 2003; Valero et al., 2003, 2005; Argenta et al., 2005; Hershkovitz et al., 2005). Porém, os efeitos nessas e em outras características associadas à qualidade dependem da dose aplicada (Valero et al., 2005), do estádio de maturação no momento da aplicação e da espécie (Argenta et al., 2005; Watkins, 2006). Para algumas espécies, a recuperação é rápida (Cin et al., 2005). Em outras, ao invés de inibição na produção de etileno pode haver uma alteração na percepção dos tecidos a esse fitormônio (Lurie \& Weksler, 2005).

A perda de firmeza é um fenômeno crítico na maturação da graviola. A menor perda inicial de firmeza nos frutos tratados pode representar um ganho posterior na vida útil (Figura 2A). O uso da cera, do 1-MCP ou de ambos reteve a firmeza principalmente entre o quarto e o oitavo dia, quando as mudanças foram mais acentuadas. O período coincidiu com o aumento que resultou no pico climatérico (Figura 1A) e com o aumento da produção de etileno (Figura 1B).

Respostas semelhantes foram registradas em nectarinas (Ziosi et al., 2005). Segundo os autores, o 1MCP exerceu uma inibição do amaciamento marcante mas transitória, sob temperatura ambiente. Em maçã (cvs Royal Gala e Golden Delicious) e pêssego (cv Summer Rich), a firmeza foi mantida durante vinte e quatro dias de armazenamento a $20^{\circ} \mathrm{C}$ e somente enquanto os frutos estiveram submetidos ao gás, respectivamente (Cin et al., 2005). Os autores sugerem que, nesse caso, respostas distintas provavelmente refletem diferenças na percepção do etileno, na organização das famílias gênicas de receptores membranares desse fitormônio e na via de transdução do sinal. Outra possibilidade é a de que a afinidade dos sítios receptores pelo etileno ou pelo 1-MCP mude ao longo do tempo (Argenta et al., 2005). 
Comparando-se a eficiência da cera ou do 1-MCP sobre a firmeza, verificou-se equivalência. A opção entre eles seria subsidiada pelos efeitos que promovem em outras variáveis.

Em abacate, Jeong et al. (2003) observaram que o amaciamento dos frutos tratados com cera, 1-MCP ou cera +1 -MCP foi mais lento. Esses tratamentos aumentaram a vida útil em dois e quatro dias, respectivamente, para os frutos que receberam cera e 1MCP ou cera + 1-MCP. Corroborando a afirmação de que o amaciamento é um dos processos que melhor respondem ao 1-MCP (Hershkovitz et al., 2005), ameixas expostas a esse gás mantiveram-se firmes durante vinte $\mathrm{e}$ oito dias de armazenamento refrigerado (Valero et al., 2003). Sob temperatura ambiente, o amaciamento ocorreu regularmente, mesmo sem aumento da emissão de etileno. Os autores sugerem que mecanismos não hormonais podem estar envolvidos.

Os frutos recém-colhidos tiveram teor de amido equivalente a 8,37\% (Figura 3A). A atividade de degradação foi de tal forma intensa que, após oito dias de armazenamento, o teor correspondia a apenas $31 \%$ do inicial. Novamente, o período entre o quarto e o oitavo dia correspondeu à maior degradação, sendo seguido por uma fase de redução mais lenta.

Os valores obtidos concordam com observações de Paull et al. (1983). Sendo o amido um dos elementos que contribuem para a firmeza (Ali et al., 1995), observou-se coincidência entre a maior degradação do primeiro e as mudanças mais críticas na última (Figura 2A).
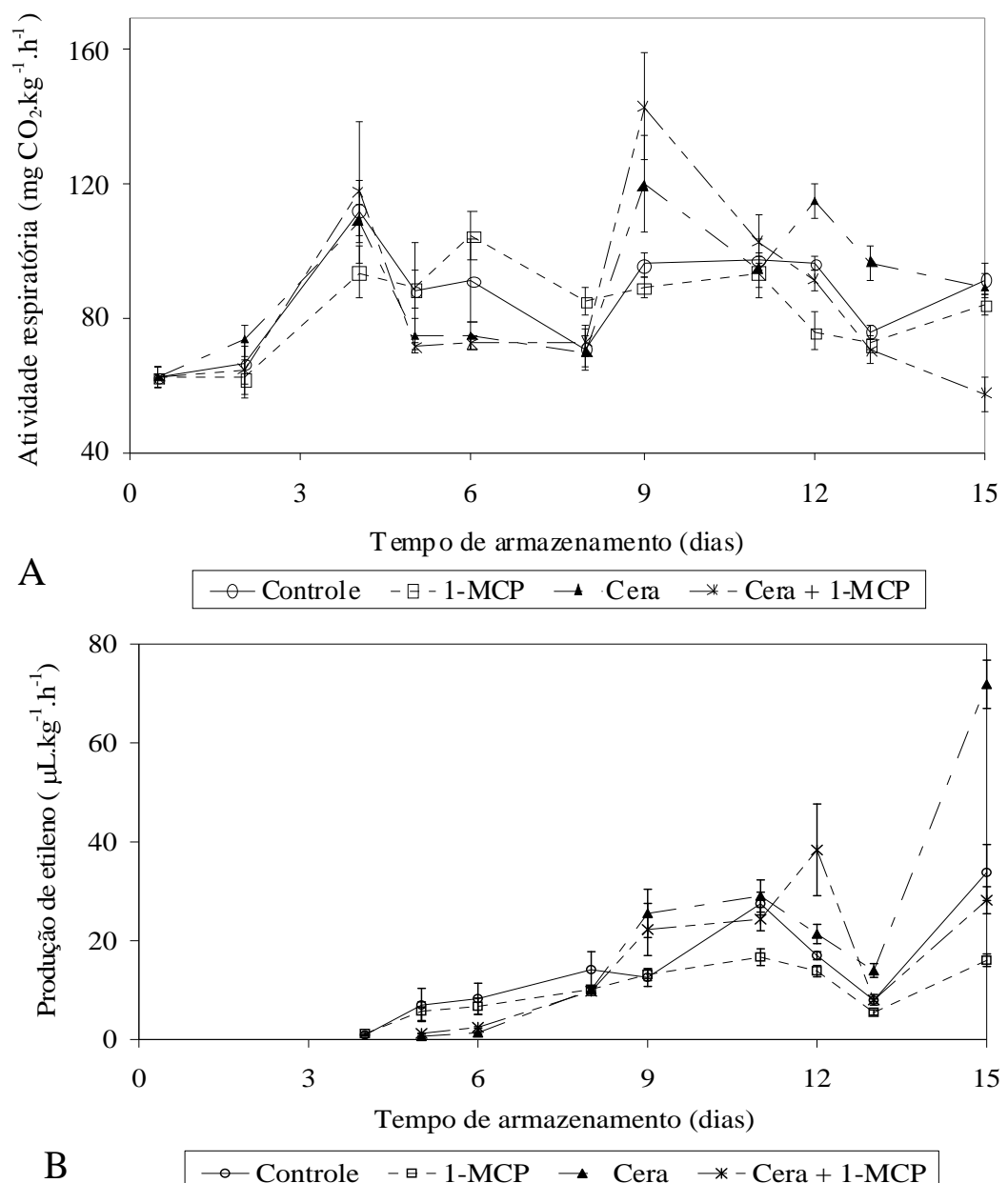

Figura 1- Atividade respiratória (A) e produção de etileno (B) em graviola 'Morada' submetida a aplicações de 1-MCP e cera e armazenada sob refrigeração $\left(15,4 \pm 1,1^{\circ} \mathrm{C}\right.$ e $86 \pm 7 \%$ UR). As barras verticais representam os erros padrões da média. 


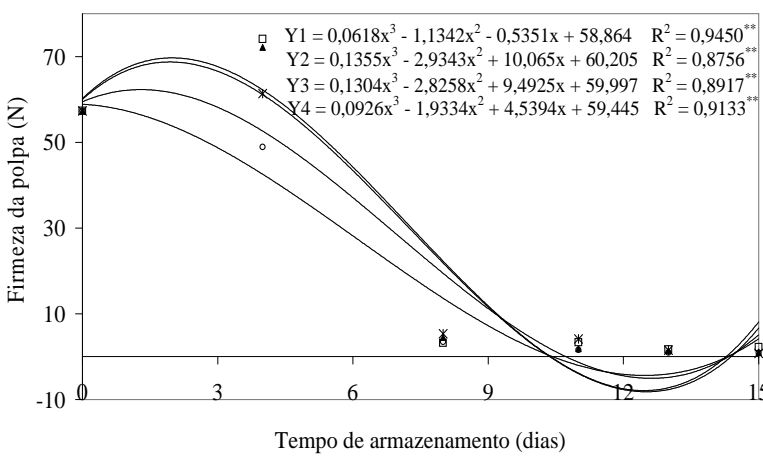

A $\circ$ Controle $(\mathrm{Y} 1)$ $1-\mathrm{MCP}(\mathrm{Y} 2) \bullet$ Cera $(\mathrm{Y} 3) *$ Cera $+1-\mathrm{MCP}(\mathrm{Y} 4)$

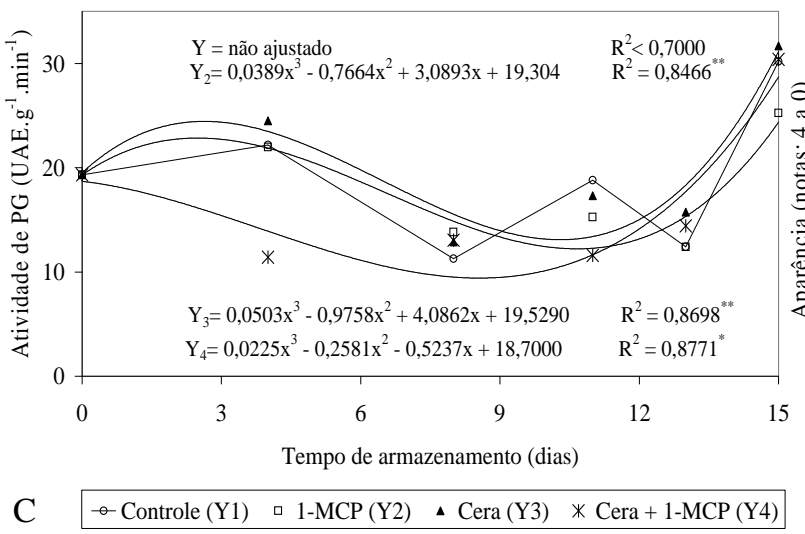

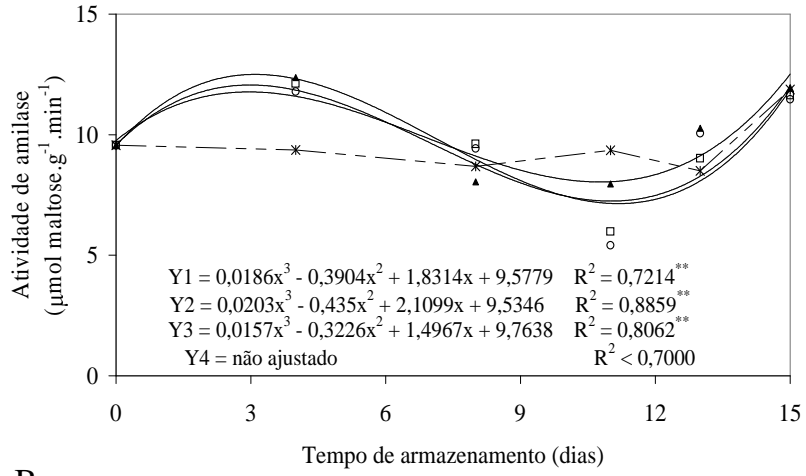

B

- Controle (Y1) व 1-MCP (Y2) ^ Cera (Y3) * Cera + 1-MCP (Y4)

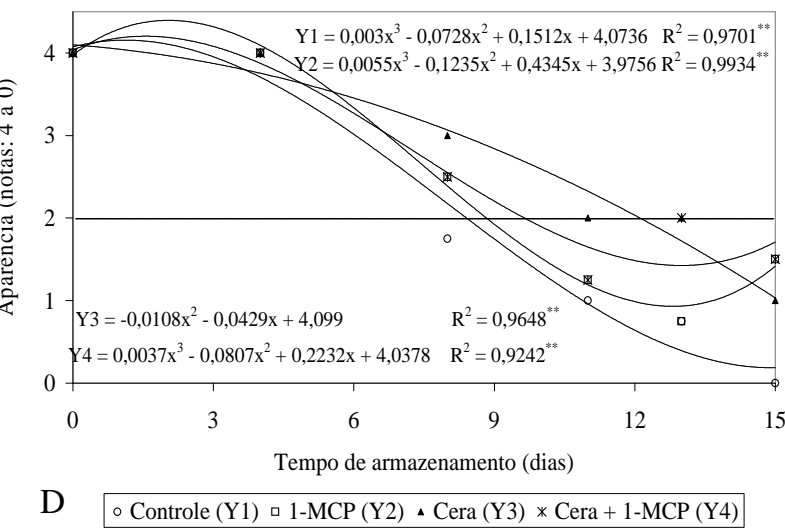

Figura 2 - Firmeza da polpa (A), atividade de amilase (B), atividade de poligalacturonase - PG - (C) e aparência (D) de graviola 'Morada' submetida a aplicações de 1-MCP e cera e armazenada sob refrigeração (15,4 $\pm 1,1^{\circ} \mathrm{C}$ e $86 \pm 7 \%$ UR). Em D, a linha paralela ao eixo x representa o limite de aceitação do consumidor.

Considerando que a degradação de amido iniciou logo após a colheita, provavelmente ela não foi estimulada pelo etileno, cuja produção começou a ser detectada a partir do quarto dia. O fato pode explicar por que a aplicação de 1-MCP não alterou a taxa degradativa do amido. Contudo, em alguns frutos, o 1-MCP atrasa significativamente essa degradação (Watkins, 2006). Em maçã, por exemplo, Crouch et al. (2005) destacam que os resultados são mais efetivos se as aplicações são realizadas quando a degradação de amido ainda é lenta.

A degradação de amido nos frutos envolve a ação de enzimas como $\alpha$-amilase, $\beta$-amilase, amido fosforilase $\mathrm{e}$ $\alpha$-glicosidase. A ação cooperativa dessas enzimas libera oligossacarídeos e, posteriormente, maltose, glicose e glicose-1-fosfato (Irving et al., 1999).

A atividade da amilase aumentou até o quarto dia de armazenamento no controle e nos tratamentos com 1-MCP e cera isoladamente (Figura 2B). Os frutos que receberam cera +
1-MCP mantiveram atividade praticamente estável até o oitavo dia, quando se verificou aumento transitório. Ao final do período, a atividade foi equivalente em todos os tratamentos.

É provável que o aumento inicial na atividade da amilase tenha sido suficiente para desencadear a degradação do amido e que a atividade residual, posterior ao valor máximo, mantenha o processo, que dispõe de teores do substrato cada vez menores.

Aumentos na atividade da amilase durante o amadurecimento da graviola foram observados por Paull et al. (1983). Estudos realizados por Lima et al. (2006) indicaram que o período de maior atividade da amilase em graviola 'Crioula' coincidiu com a maior degradação do amido. Esse aumento pode estar relacionado à interrupção da translocação de carboidratos produzidos nas folhas para o fruto, por ocasião da colheita. Essa interrupção representaria o sinal que desencadearia a degradação do amido (Irving et al., 1999). 
LIMA, M. A. C. de et al.
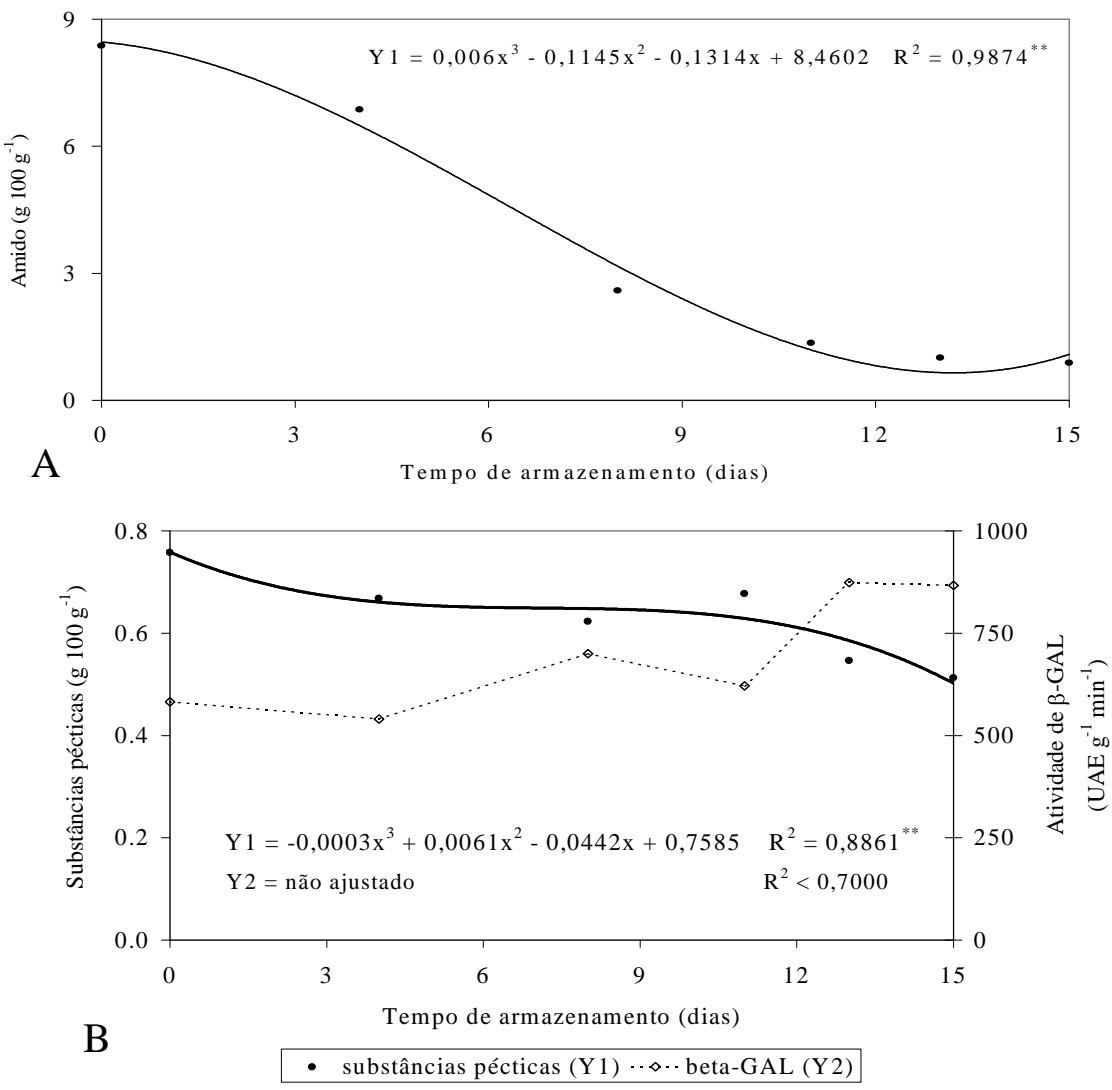

Figura 3 - Teor de amido (A), substâncias pécticas totais e atividade de $\beta$-galactosidase - $\beta$-GAL - (B) de graviola 'Morada' durante o armazenamento refrigerado $\left(15,4 \pm 1,1^{\circ} \mathrm{C}\right.$ e $86 \pm 7 \%$ UR). Valores médios dos tratamentos póscolheita aplicados.

O teor de substâncias pécticas totais não sofreu influência dos tratamentos pós-colheita (Figura 3B). Observou-se queda inicial até o quarto dia, seguida por fase praticamente estável. Após o décimo primeiro dia, verificou-se decréscimo até o valor de $0,51 \%$.

Aziz \& Yusof (1994) verificaram queda nos teores de pectina durante o amadurecimento da graviola. Em geral, essas alterações estão associadas à degradação enzimática. Porém, a estrutura da molécula, que também apresenta ligações nãocovalentes, reforça a possibilidade de degradação não enzimática (Giovannoni, 2001).

A atividade da $\beta$-GAL apresentou tendência de aumento por até treze dias, sendo os maiores incrementos verificados entre o quarto e o oitavo dia e entre o décimo primeiro e o décimo terceiro dia (Figura 3B). A fase de primeiro aumento coincidiu com a queda brusca da firmeza (Figura 2A), sugerindo que a enzima é importante no processo, provavelmente atuando em conjunto com outras hidrolases. Após o décimo terceiro dia, a atividade estabilizou, concordando com o completo amaciamento.

A interferência da $\beta$-GAL no amadurecimento está relacionada à remoção de cadeias laterais contendo galactose, provavelmente arabinogalactanas, o que facilita a degradação de poliuronídeos (Ali et al., 1995). Consequentemente, menores atividades dessa enzima seriam esperadas sob condições ou tratamentos que atrasassem o amaciamento (Watkins, 2006).

A atividade da PG foi influenciada pelos tratamentos pós-colheita até o décimo primeiro dia (Figura $2 \mathrm{C}$ ). $\mathrm{O}$ efeito foi mais evidente no tratamento cera+1-MCP, caracterizado por menor atividade. Nos demais, o aumento inicial coincidiu com a redução do conteúdo de pectina (Figura $3 B$ ) e antecedeu à fase de maior queda na firmeza (Figura 2A). O aumento posterior foi mais precoce nos frutos controle e pode estar relacionado à senescência. 
Em alguns frutos, a limitação do amaciamento resultante da ação de 1-MCP está associada a menores atividades de hidrolases da parede celular, como a PG (Watkins, 2006). Em abacate, associando-se ao 1-MCP a aplicação de cera, a atividade da PG se mantém baixa. Contudo, o efeito deve ser atribuído ao 1-MCP já que frutos tratados apenas com cera exibem aumentos na atividade dessa enzima comparáveis aos nãotratados (Jeong et al., 2003).

Em se tratando de amaciamento, uma ação coletiva e sinergística de várias enzimas seria necessária para promover mudanças relevantes. Adicionalmente, outros agentes, como proteínas não enzimáticas, também contribuem para o processo (Giovannoni, 2001).

Em graviola, Lima et al. (2006) destacaram a importância da PG e da $\beta$-GAL para o amaciamento. Os autores sugeriram maior atuação da PG no início do processo. A partir daí, a queda precoce de atividade da PG sugere que a $\beta$-GAL caracteriza melhor a transformação.

A aparência também foi influenciada pelos tratamentos (Figura 2D). Os frutos controle tiveram aparência comprometida aos oito dias. Nessa ocasião, os frutos tratados com 1-MCP eram comercializáveis embora, quando atingiram o décimo primeiro dia, a aparência já os depreciasse. O mesmo foi observado nos frutos que receberam cera+1-MCP. Aqueles tratados com cera mantiveram aparência aceitável para consumo até o décimo terceiro dia.

Resultados similares foram obtidos por Silva et al. (2001), que observaram graviolas de boa aparência após doze dias de armazenamento sob atmosfera modificada, a $14^{\circ} \mathrm{C}$.

\section{CONCLUSÕES}

Tratamentos pós-colheita com cera, 1-MCP ou ambos retiveram a firmeza da polpa durante o período em que ocorrem as mudanças bioquímicas mais acentuadas na graviola, resultantes, por exemplo, do aumento da atividade da $\beta$-galactosidase e do primeiro pico de $\mathrm{CO}_{2}$.

A aplicação isolada do 1-MCP atrasou o pico respiratório e limitou a produção de etileno em graviola. Quando associada à cera, adicionou os efeitos de manter a atividade da amilase estável e reduzir a atividade da PG. Em ambas os casos, manteve a aparência por onze dias.

A aplicação de cera em graviola manteve a aparência aceitável para consumo por treze dias.

\section{REFERÊNCIAS BIBLIOGRÁFICAS}

ALI, Z.M.; ARMUGAM, S.; LAZAN, H. $\beta$-galactosidase and its significance in ripening mango fruit.

Phytochemistry, Oxford, v.38, n.5, p.1109-1114, Mar. 1995.
ARGENTA, L.C.; FAN, X.F.; MATHEIS, J.P. Factors affecting efficacy of 1-MCP to maintain quality of apples fruit after storage. Acta Horticulturae, Brugg, v.682, n.2, p.1249-1255, 2005.

\section{ASSOCIATION OF OFFICIAL AGRICULTURAL CHEMISTS. Official methods of analysis of the Association of the Agricultural Chemistry. 11.ed. Washington, 1992. 1115p.}

AZIZ, P.A.; YUSOF, S. Physico-chemical characteristics of soursop fruit (Annona muricata) during growth and development. ASEAN Food Journal, New York, v.9, n.4, p.147-150, Oct./Dec. 1994.

BERNFELD, P. Enzymes in carboydrate metabolism. In: COLWICK, S.P.; KAPLAN, N.O. (Eds.). Methods in enzimology. New York: Academic, 1955. v.1, p.149-150.

BLUMENKRANTZ, N.; ASBOE-HANSEN, G. New method for quantitative determination of uronics acids. Analytical Biochemistry, New York, v.54, n.2, p.484-489, Aug. 1973.

CIN, V. dal; RIZZINI, F.M.; BOTTON, A.; ZILIOTTO, F.; DANESIN, M.; TONUTTI, P. Different response of apple and peach fruits to 1-MCP: a case of different sensitivity to ethylene? Acta Horticulturae, Brugg, v.682, n.1, p.321-327, 2005.

\section{CROUCH, I.; SNIJMAN, H.; TAAIBOSCH, A.}

Commercialisation of SmartFresh ${ }^{\circledR}$ (1-methylcyclopropene) in the South African apple export market, and its effect on post-harvest handling and quality. Acta Horticulturae, Brugg, v.682, n.1, p.349-353, 2005.

DEY, P.M.; PRIDHAM, J.B. Purification and properties of a-galactosidases from Vicia faba seeds. Biochemistry Journal, London, v.113, n.1, p.49-55, Jan. 1969.

ERGUN, M.; SARGENT, S.A.; FOX, A.J.; CRANE, J.H.; HUBER, D.J. Ripening and quality responses of mamey sapote fruit to postharvest wax and 1methylcyclopropene treatments. Postharvest Biology and Technology, Amsterdam, v.36, n.2, p.127-134, May 2005.

GIOVANNONI, J. Molecular biology of fruit maturation and ripening. Annual Review of Plant Physiology and Plant Molecular Biology, Palo Alto, v.52, p.725-749, 2001. 
HERSHKOVITZ, V.; SAGUY, S.I.; PESIS, E. Postharvest application of 1-MCP to improve the quality of various avocado cultivars. Postharvest Biology and Technology, Amsterdam, v.37, n.3, p.252-264, Sept. 2005.

IRVING, D.E.; SHINGLETON, G.J.; HURST, P.L. Starch degradation in buttercup squash (Cucurbita maxima). Journal of the American Society for Horticultural Science, Alexandria, v.124, n.6, p.587-590, Nov./Dec. 1999.

JEN, J.J.; ROBINSON, M.L.P. Pectolytic enzymes in sweet bell peppers (Capsicum annuиm L.). Journal of Food Science, Chicago, v.49, n.4, p.1045-1087, 1984.

JEONG, J.; HUBER, D.J.; SARGENT, S.A. Delay of avocado (Persea americana) fruit ripening by 1methylcyclopropene and wax treatments. Postharvest Biology and Technology, Amsterdam, v.28, n.3, p.247-257, June 2003.

KHADER, S.E.S.A. Effect of gibberellic acid and vapor gard on ripening amylase and peroxidase activities and quality of mango fruits during storage. Journal of Horticultural Science, Ashford, v.67, n.6, p.855-860, Nov. 1992.

KITAGAWA, Y.; KANAYAMA, Y.; YAMAKI, S. Isolation of b-galactosidase fractions from Japanese pear: activity against native cell wall polysaccharides. Physiologia Plantarum, Copenhagen, v.93, n.3, p.545550, Mar. 1995.

LIMA, M.A.C. de; ALVES, R.E.; FILGUEIRAS, H.A.C. Mudanças relacionadas ao amaciamento da graviola (Annona muricata L.) durante a maturação pós-colheita. Pesquisa Agropecuária Brasileira, Brasília, v.41, n.12, p.1707-1713, dez. 2006.

LIMA, M.A.C. de; ALVES, R.E.; FILGUEIRAS, H.A.C.; LIMA, J.R.G. Uso de cera e 1-metilciclopropeno na conservação refrigerada de graviola (Annona muricata L.). Revista Brasileira de Fruticultura, Jaboticabal, v.26, n.3, p.433-437, set./dez. 2004.

LURIE, S.; WEKSLER, A. Effects of 1methylcyclopropene on stone fruits. Acta Horticulturae, Brugg, v.682, n.1, p.85-90, 2005.
McREADY, P.M.; McCOMB, E.A. Extraction and determination of total pectin materials. Analytical Chemistry, Columbus, v.24, n.12, p.1586-1588, Dec. 1952.

MILLER, G.L. Use of dinitrosalicylic acid reagent for determination of reducing sugars. Analytical Chemistry, Columbus, v.31, n.3, p.426-428, Mar. 1959.

PAULL, R.E.; DEPUTY, J.; CHEN, N.J. Changes in organic acids, sugars, and headspace volatiles during fruit ripening of soursop. Journal of the American Society for Horticultural Science, Alexandria, v.108, n.6, p.931-934, Nov./Dec. 1983.

SILVA, S.M.; MARTINS, L.P.; SANTOS, J.G. dos S.; ALVES, R.E. Conservação pós-colheita de frutos de graviola (Annona muricata L.) sob atmosfera modificada. Revista Iberoamericana de Tecnología Postcosecha, Hermosillo, v.4, n.1, p.6-12, enr. 2001.

SISLER, E.C.; SEREK, M. Inhibitors of ethylene responses in plants at the receptor level: recent developments. Physiologia Plantarum, Copenhagen, v.100, n.3, p.577-582, July 1997.

VALERO, D.; GUILLÉN, F.; VALVERDE, J.M.; MARTÍNEZ-ROMERO, D.; CASTILLO, S.; SERRANO, M. 1-MCP use on Prunus spp. to maintain fruit quality and to extend shelf life during storage: a comparative study. Acta Horticulturae, Brugg, v.682, n.2, p.933-940, 2005.

VALERO, D.; MARTÍNEZ-ROMERO, D.; VALVERDE, J.M.; GUILLÉN, F.; SERRANO, M. Quality improvement and extension of shelf life by 1-methylcyclopropene in plum as affected by ripening stage at harvest. Innovative Food Science and Emerging Technologies, Amsterdam, v.4, n.2, p.339-348, June 2003.

WATKINS, C.B. The use of 1-methylcyclopropene (1$\mathrm{MCP})$ on fruits and vegetables. Biotechnology Advances, Amsterdam, v.24, n.4, p.389-409, July/Aug. 2006.

ZIOSI, V.; BIONDI, S.; TORRIGIANI, P.; RASORI, A.; BREGOLI, A.M.; COSTA, G. 1-MCP effects in nectarines: dependence on storage temperature, and relationship with polyamines. Acta Horticulturae, Brugg, v.682, n.2, p.1241-1247, 2005 . 